\title{
The flattened and needlelike leaves of the pine family (Pinaceae) share a conserved genetic network for adaxial-abaxial polarity but have diverged for photosynthetic adaptation
}

\author{
Hong Du', Jin-Hua Ran ${ }^{1,2}$, Yuan-Yuan Feng ${ }^{1,2}$ and Xiao-Quan Wang ${ }^{1,2^{*}}$
}

\begin{abstract}
Background: Leaves have highly diverse morphologies. However, with an evolutionary history of approximately 200 million years, leaves of the pine family are relatively monotonous and often collectively called "needles", although they vary in length, width and cross-section shapes. It would be of great interest to determine whether Pinaceae leaves share similar morpho-physiological features and even consistent developmental and adaptive mechanisms.

Results: Based on a detailed morpho-anatomical study of leaves from all 11 Pinaceae genera, we particularly investigated the expression patterns of adaxial-abaxial polarity genes in two types of leaves (needlelike and flattened) and compared their photosynthetic capacities. We found that the two types of leaves share conserved spatial patterning of vasculatures and genetic networks for adaxial-abaxial polarity, although they display different anatomical structures in the mesophyll tissue differentiation and distribution direction. In addition, the species with needlelike leaves exhibited better photosynthetic capacity than the species with flattened leaves.
\end{abstract}

Conclusions: Our study provides the first evidence for the existence of a conserved genetic module controlling adaxial-abaxial polarity in the development of different Pinaceae leaves.

Keywords: Pinaceae, Leaf anatomy, Adaxial-abaxial polarity, Polarity gene, Developmental mechanism, Adaptive evolution, Photosynthesis

\section{Background}

Most extant genera of conifers, the largest lineage of gymnosperms, originated in the middle and late Mesozoic, while a majority of extant species recently diverged until the Neogene and are now widely distributed throughout the world except Antarctica [1-4]. Conifers

\footnotetext{
* Correspondence: xiaoq_wang@ibcas.ac.cn

${ }^{1}$ State Key Laboratory of Systematic and Evolutionary Botany, Institute of Botany, the Chinese Academy of Sciences, 20 Nanxincun, Xiangshan, Beijing 100093, China

${ }^{2}$ University of Chinese Academy of Sciences, Beijing 100049, China
}

are characterized by their distinct leaves, i.e., "needles", which underwent convergent or parallel evolution over a long history to adapt to different environments, and these leaves show two main types, needlelike and flattened leaves (including scale-like leaves). Generally, needlelike leaves appear to be more drought-resistant than flattened leaves $[5,6]$. Previous studies on conifer "needles" have evaluated their morphology and physiology [7-9] but rarely focused on their developmental mechanisms and evolution. Pinaceae (the pine family),

(c) The Author(s). 2020 Open Access This article is licensed under a Creative Commons Attribution 4.0 International License, which permits use, sharing, adaptation, distribution and reproduction in any medium or format, as long as you give appropriate credit to the original author(s) and the source, provide a link to the Creative Commons licence, and indicate if changes were made. The images or other third party material in this article are included in the article's Creative Commons licence, unless indicated otherwise in a credit line to the material. If material is not included in the article's Creative Commons licence and your intended use is not permitted by statutory regulation or exceeds the permitted use, you will need to obtain permission directly from the copyright holder. To view a copy of this licence, visit http://creativecommons.org/licenses/by/4.0/ The Creative Commons Public Domain Dedication waiver (http://creativecommons.org/publicdomain/zero/1.0/) applies to the data made available in this article, unless otherwise stated in a credit line to the data. 
comprising 11 genera and approximately 230 species, is the most important component of the coniferous forests in the Northern Hemisphere, with both needlelike and flattened leaves $[4,10,11]$. However, it is difficult to study the molecular mechanisms underlying the evolution and development of some important traits of this family due to the large genome size, high heterozygosity and long generation time of Pinaceae [12-14].

Compared to the scarce literature on gymnosperms, leaf developmental mechanisms have been extensively studied in angiosperms. In general, angiosperm leaves develop as bifacial structures with distinct adaxial and abaxial identities, which enables the maximum photosynthetic rate [15-18]. As early as 1995, Waites and Hudson proposed a hypothesis that lamina outgrowth is promoted at the juxtaposition between adaxial and abaxial identities [19]. Then, several distinct regulators involved in leaf adaxial-abaxial polarity specification were identified, such as the adaxial determinants of the HDZIPIII family, AS1-AS2 and miR165/166, and the abaxial determinants of ETT/ARF3, ARF4, the YABBY family and the KANADI family [19-25]. The miR165/166 can degrade $H D$-ZIPIII in the abaxial domain, leading to the exclusive accumulation of its transcripts in the adaxial domain [26]. The AS1-AS2 complex could repress the expression of abaxial genes, such as KAN2, YAB5, ETT/ $A R F 3$ and $A R F 4$ [22, 27], and simultaneously degrade the transcripts of ETT/ARF3 and ARF4 by the small RNA tasiR-ARF in the adaxial domain, ultimately contributing to the determination of the adaxial cell fate $[28,29]$. The mutually antagonistic interactions between the adaxial and abaxial identity regulators determine the dorsoventrally flattened structure of conventional bifacial leaves. Interestingly, a kind of unifacial leaf also exists in angiosperms, which is characterized by only an abaxialized identity usually with a radially symmetric, cylindrical structure [30-32]. In addition, the absence of the adaxial identity in bifacial leaves usually gives rise to cylindrical leaves, similar to those of unifacial leaves. Thus, it is intriguing to explore when the molecular genetic mechanism for specifying leaf adaxial-abaxial polarity originated, whether conifer "needles" are also regulated by this mechanism and whether this mechanism is conserved between the needlelike and flattened leaves in conifers. In recent years, with the development of high-throughput sequencing technologies, several genomes of gymnosperms, especially Pinaceae, have been released [12-14, 33], providing a good opportunity to disentangle how Pinaceae leaves genetically developed to different types.

Generally, variations in leaf morphology and structure are closely related to changes in physiological function, which reflect adaptations to different environments [34-36]. In gymnosperms, some previous studies indicated that the species of the pine family with needlelike leaves exhibited a higher photosynthetic rate than Podocarpaceae with flattened leaves $[5,37]$, which reflected that narrow or needle leaves were suited to sunny and dry environments, whereas broader leaves were adapted to typically shady and humid habitats [5, 37]. In addition, a recent study on Cupressaceae demonstrated that most species in the Cupressoid and Callitroid clades, which have appressed, imbricate leaves, were more drought-tolerant than other clades with flattened leaves [6]. Meanwhile, this study found that a relatively low photosynthetic capacity was presumably related to the small, thick-walled conduits [6]. Therefore, examination of the correlation between leaf morphology and physiological function, such as photosynthetic capacity, appears to be crucial for understanding the evolution and adaptation of Pinaceae with different types of leaves.

In this study, we investigated the developmental mechanisms and adaptive evolution of Pinaceae leaves. Based on a detailed morpho-anatomical experiment, the flattened and needlelike leaves were structurally characterized. Then, we investigated the phylogenetic relationships and expression patterns of polarity genes to test whether the developmental program for specifying leaf adaxial-abaxial polarity diverged in the two types of Pinaceae leaves. Moreover, the correlation between leaf morphology and photosynthetic capacity was examined to understand how Pinaceae have made morphological and physiological adjustments to better adapt to different habitats.

\section{Results}

\section{Morphological and anatomical divergence of Pinaceae leaves}

Based on the width/thickness ratio (WTR) of the cross section, Pinaceae leaves could be mainly divided into two types, needlelike (mean WTR $<2$ ) and flattened (mean WTR $>2$ ) (Fig. 1a and Additional file 1: Figure S1). Leaves of the selected species of Cedrus, Picea and Pinus, except for Picea brachytyla var. complanata and Pinus krempfii, belonged to the needlelike type, which were quadrangular, triangular or semicircular, and it was difficult to distinguish the adaxial or abaxial side, while samples from the remaining eight genera (Abies, Cathaya, Keteleeria, Larix, Nothotsuga, Pseudolarix, Pseudotsuga and Tsuga), as well as Picea brachytyla var. complanata and Pinus krempfii exhibited flattened and dorsoventrally asymmetric leaves (Fig. 1a and Additional file 1: Figure S1).

Anatomical observation by SEM indicated that the two types of leaves in Pinaceae each have distinct structural characteristics. In the flattened leaves, the mesophyll 


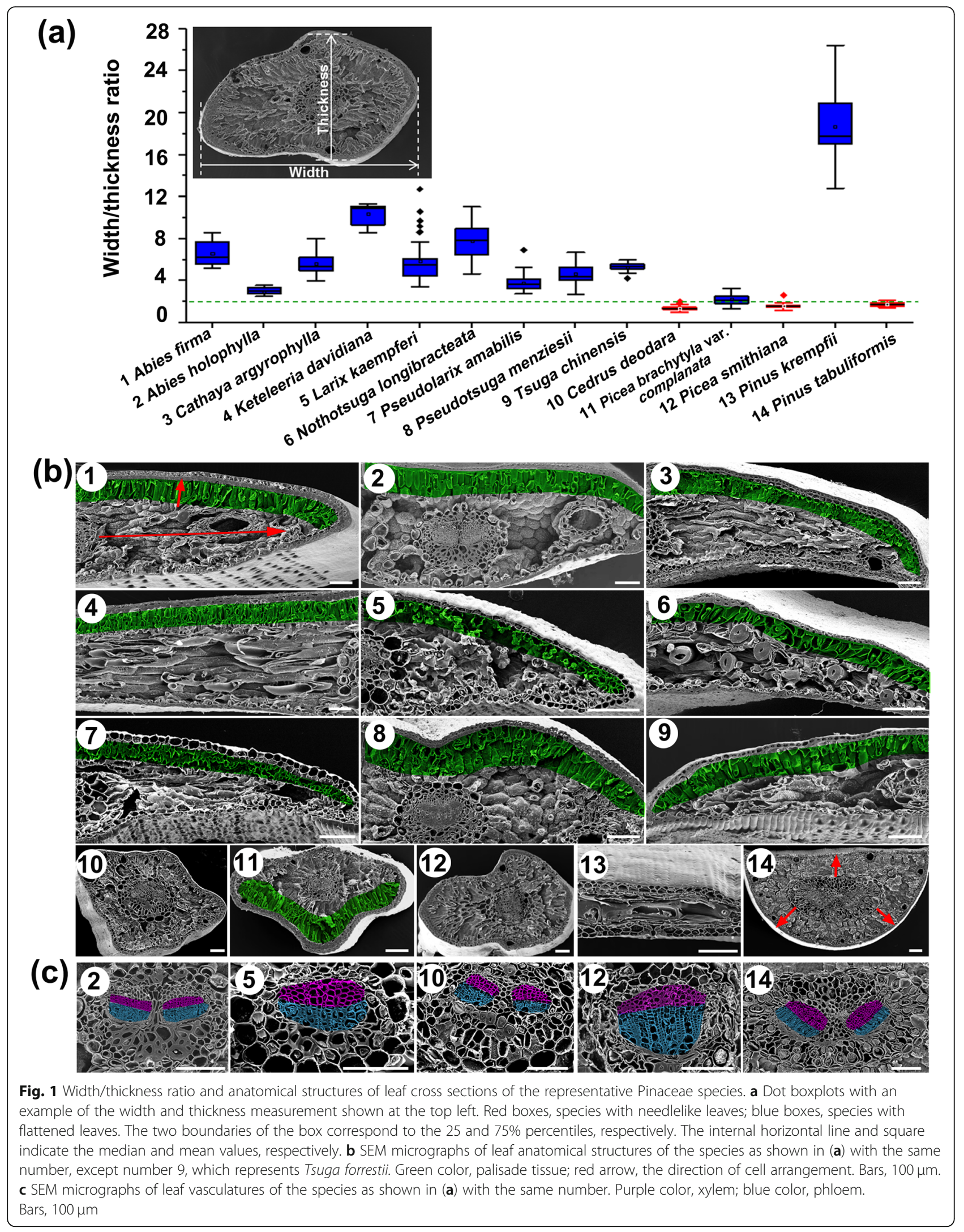


cells differentiated into asymmetric, adaxial-abaxial structures of palisade (green color) and spongy tissues (Fig. 1b, species 1-9 and 11). Two directions of mesophyll cells were uniformly aligned, with elongated palisade cells perpendicular to the adaxial surface and several layers of spongy cells along the mediolateral axis adjacent to the abaxial side (Fig. 1b, e.g., the red arrows in species 1), however, the arrangement pattern of mesophyll cells was opposite in Picea brachytyla var. complanata (Fig. 1b, species 11). Another exception was Pinus krempfii, which has flattened leaves, but adaxial palisade cells were not found in its leaves (Fig. 1b, species 13). In contrast, in the needlelike leaves, the mesophyll cells were generally homogeneous without obvious adaxialabaxial divergence and radially distributed from the middle vascular bundle toward the leaf surface (Fig. 1b, species 10, 12, 14, e.g., the red arrows in species 14).

In addition, sclereids were found in three species, i.e., Pinus krempfii, Pseudotsuga menziesii, and Nothotsuga longibracteata (Additional file 2: Figure S2, Additional file 3: Video S1, Additional file 4: Video S2 and Additional file 5: Video S3), which are known for radially transporting water from the vein to the margin [36]. In Pinus krempfii, the sclereids were cylindrical and midrib-vertically, discontinuously arranged in the mesophyll (Additional file 2: Figure S2a and Additional file 3: Video S1). Likewise, the sclereids in Pseudotsuga menziesii were also midribvertical but star-shaped and connected to the parenchymatous endodermis (Additional file 2: Figure S2b and Additional file 4: Video S2). However, in Nothotsuga longibracteata, their sclereids were midribparallel, unbranched and lignified tubules, possessing thick walls, short internal diameters and long lengths comparable to the leaf length (Additional file 2: Figure S2c and Additional file 5: Video S3).

\section{Spatial adaxial-abaxial pattern of vasculatures in Pinaceae leaves}

The spatial distribution of leaf vasculatures is important for distinguishing the adaxial-abaxial polarity of leaves [16]. One (Fig. 1c, Larix kaempferi and Picea smithiana) or two (Fig. 1c, Abies holophylla, Cedrus deodara and Pinus tabuliformis) vascular bundles, separated by several layers of parenchyma cells, were observed. The xylem tissues (purple color) differentiated toward the adaxial surface, while the phloem (blue color) abaxially differentiated in Pinaceae flattened leaves (Fig. 1c, Abies holophylla and Larix kaempferi). Unexpectedly, similar to the flattened leaves, the vasculatures in the needlelike leaves could also be divided into parallelly arranged xylem and phloem tissues (Fig. 1c, Cedrus deodara, Picea smithiana and Pinus tabuliformis). Phloroglucinol staining also confirmed the parallel xylem and phloem tissues in the needlelike leaves (Additional file 6: Figure S3ss).

\section{Identification and phylogenetic analysis of the polarity genes in Pinaceae}

We searched three gene families involved in the establishment of leaf adaxial-abaxial polarity, and 56, 13 and 29 sequences of HDZIPIII, AS1 and YABBY, respectively, were identified from 14 species representing all 11 genera of Pinaceae (Fig. 2). The phylogenetic analyses showed that homologs of the adaxial determinant HDZIPIII family in Pinaceae were divided into five distinct clades (GymC3HDZ_A to GymC3HDZ_E), in which GymC3HDZ_A was a sister to the angiosperm adaxial-patterning determinant AngREV+PHX clade and GymC3HDZ_D was a sister to the angiosperm AngC8 clade, whereas clades GymC3HDZ_B, GymC3HDZ_C, and GymC3HDZ_E were exclusive in gymnosperms (Fig. 2a). Besides, only one ortholog of another adaxial determinant AS1 was identified in each Pinaceae species (Additional file 7: Figure S4). For the abaxial determinant $Y A B B Y$ gene family, an unrooted tree was built because this gene family was found only in seed plants [38, 39]. The results showed that gymnosperm sequences were distributed in three moderately supported clades (GymYAB_A, GymYAB_B and GymYAB_C), while the angiosperm sequences formed an independent clade (Fig. 2b).

It is interesting that most members in the three gene families (HDZIPIII, AS1 and YABBY) occurred in almost all selected species, except the GymC3HDZ_C and GymYAB_A genes (Fig. 2c). GymC3HDZ_C genes were absent from the transcriptome databases of Pinus, Cathaya and Picea, and GymYAB_A genes were found only in the genome databases of Pinus taeda, Picea abies and Pseudotsuga menziesii (Fig. 2c).

\section{Spatiotemporal expression patterns of polarity genes in Pinaceae leaves}

The qPCR analyses indicated that all four HDZIPIII family members (GymC3HDZ_A to GymC3HDZ_D) were expressed across the three stages of leaf development, particularly with prominent expression at the first two stages (Fig. 3 and Additional file 8: Figure S5). GymC3HDZ_A, GymC3HDZ_C and GymC3HDZ_ $D$ showed similar expression levels between the species with flattened and needlelike leaves, respectively (Fig. $3 \mathrm{~b}$ and Additional file 8: Figure S5), whereas GymC3HDZ_C displayed higher expression mostly in the species with flattened leaves and a species with needlelike leaves, Picea smithiana (Additional file 8: Figure S5). In contrast to Gymnosperm HDZIPIII 


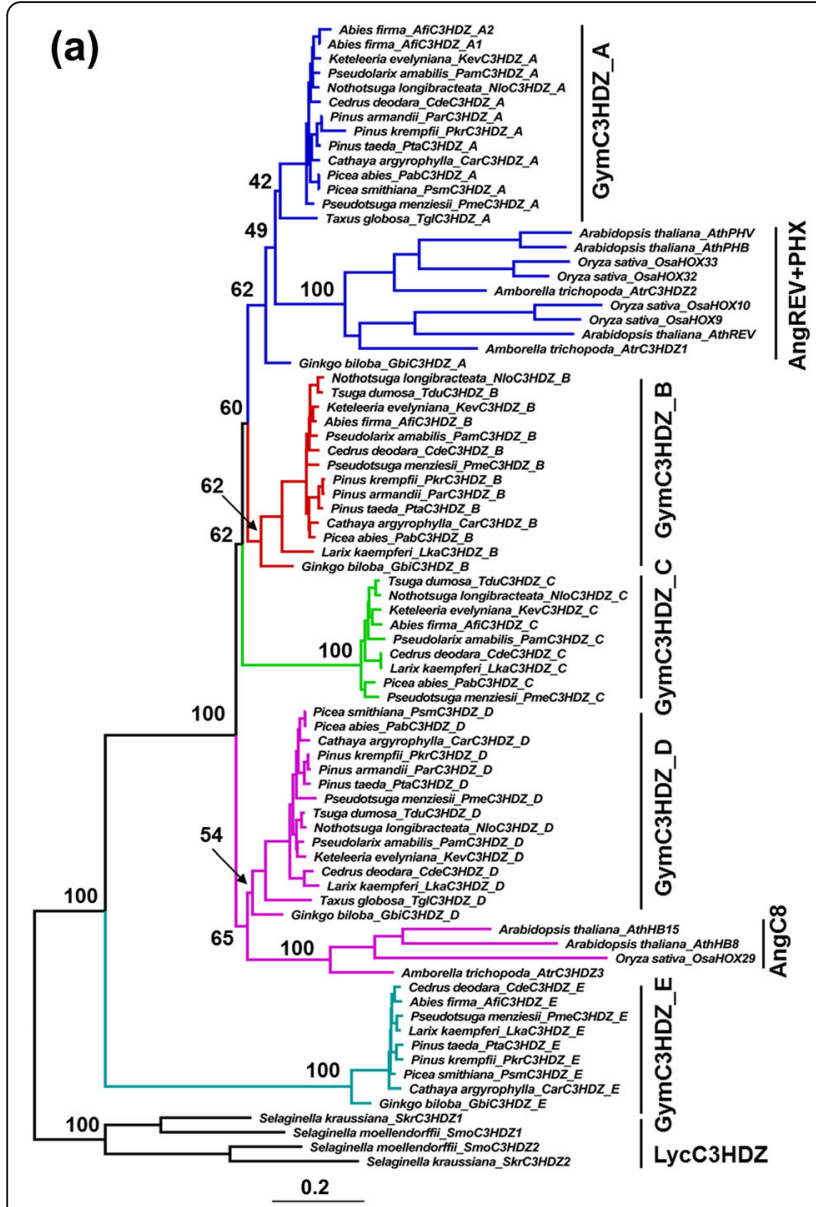

(b)

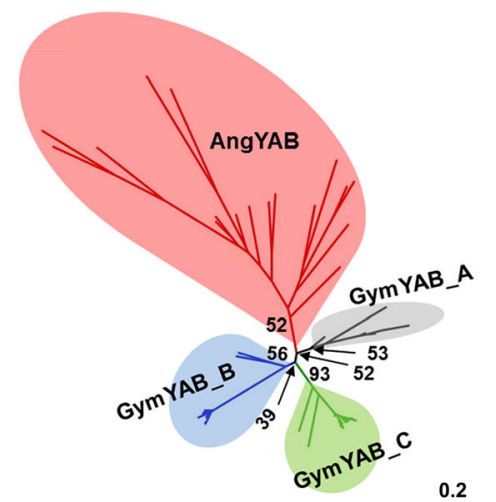

(c)

Fig. 2 Maximum likelihood (ML) trees and repertoire of polarity genes. a Rooted phylogenetic tree of the HDZIPIII genes. b Unrooted trees of YABBY genes. Ang, angiosperm; Gym, gymnosperm; Lyc, lycophytes. Numbers on the branches indicate the bootstrap values. c Repertoire of polarity genes in Pinaceae lineages. Red colors indicate the species with needlelike leaves; Black stars indicate that data were collected from the genome databases

genes, another adaxial determinant gene, GymAS1, showed the strongest expression in the species with needlelike leaves, especially in the two pines (Fig. 3b). For the $Y A B B Y$ genes, the GymYAB_C homologs exhibited the same expression level in the two types of Pinaceae leaves (Fig. 3b), which was much higher than the expression level of the GymYAB_B homologs (Additional file 8: Figure S5).

According to phylogenetic and qPCR analyses, the expression patterns of the GymC3HDZ_A, GymAS1 and GymYAB_C genes were further studied in Abies holophylla with flattened leaves and Picea smithiana with needlelike leaves by in situ hybridization. The expression signal of GymC3HDZ_A showed clear evidence of polar patterning that was restricted to the adaxial region and especially the vascular tissue in both species (Fig. 3c, the left column). The hybridization of GymAS1 in the two species showed a strong expression signal through the central region between the adaxial and abaxial domains (Fig. 3c, the middle column), whereas GymYAB_C expression was detected only in the vascular tissues of the two species and slightly in the leaf margin of the cross section of Abies holophylla (Fig. 3c, the right column).

\section{Photosynthetic performance of the two types of Pinaceae leaves}

In the "common garden" conditions, the responses of photosynthesis to two PAR gradients in the representatives of the two types of Pinaceae leaves were examined. When the PAR was $600 \mathrm{mmol} \mathrm{m}^{-2} \mathrm{~s}^{-1}$, the net carbon assimilation of the species with flattened leaves (Abies firma, Abies holophylla, Larix kaempferi, Pseudolarix amabilis and Pseudotsuga menziesii) reached approximately $2 \mu \mathrm{mol} \mathrm{m} \mathrm{m}^{-2} \mathrm{~s}^{-1}$, while the species with needlelike leaves (Cedrus deodara, Picea smithiana, Pinus armandii and Pinus tabuliformis) exhibited a high photosynthetic capacity, i.e., $3-5 \mu \mathrm{mol} \mathrm{m}{ }^{-2} \mathrm{~s}^{-1}$ (Fig. 4). Likewise, when facing a high light radiation of $1000 \mathrm{mmol} \mathrm{m}^{-2}$ $\mathrm{s}^{-1}$, the species with needlelike leaves also exhibited 


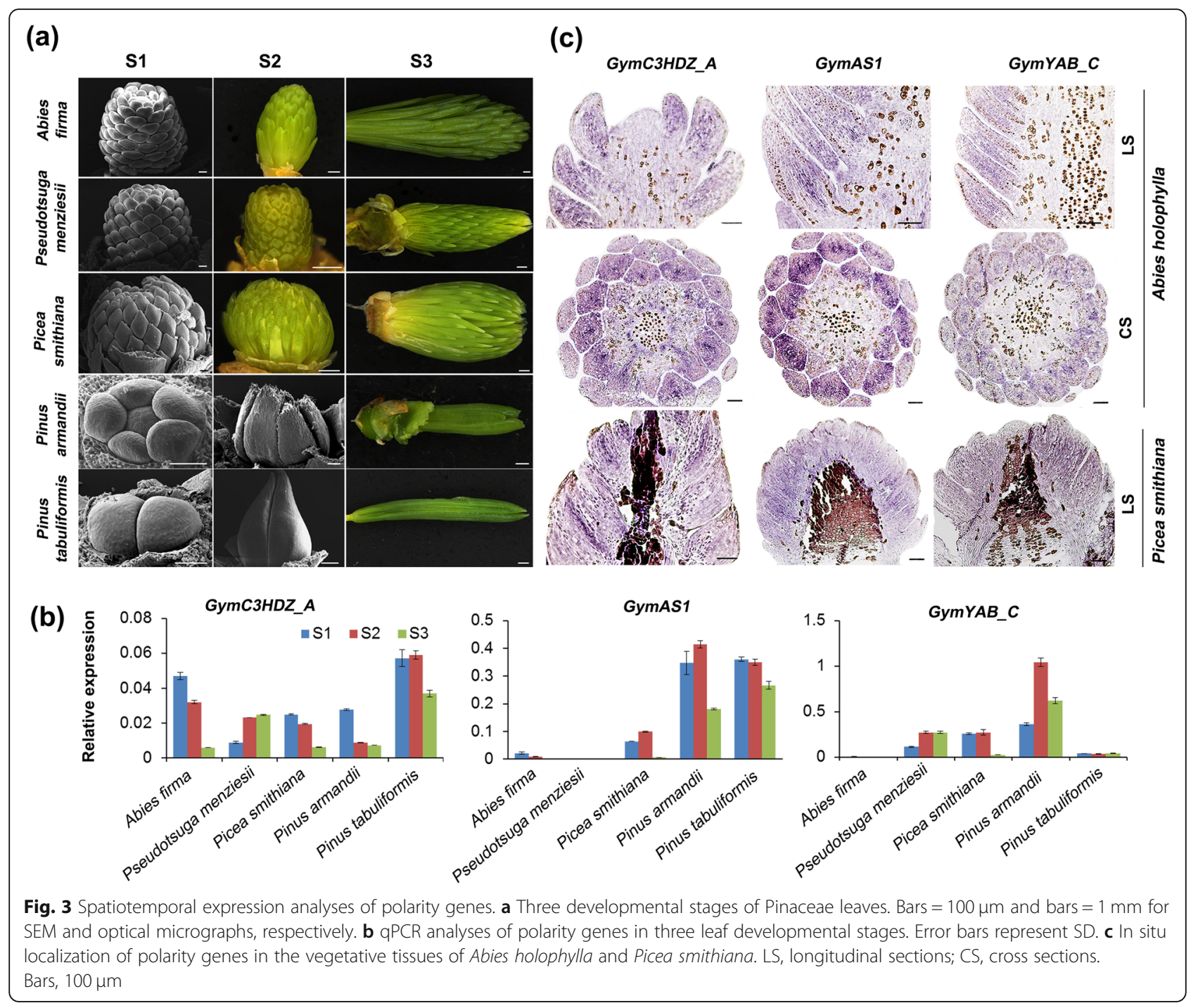

better photosynthetic capacity than the species with flattened leaves (Fig. 4). Similarly, the measurement of stomatal conductance and the transpiration rate showed relatively high values in the species with needlelike leaves (Additional file 9: Figure S6).

\section{Discussion}

A conserved adaxial-abaxial specifying mechanism exists in the development of different leaves in Pinaceae

Although the commonly known "needles" vary greatly in shape in Pinaceae, these leaves can be classified into two types, i.e., needlelike and flattened, based on the transverse WTR (Fig. 1a and Additional file 1: Figure S1). Structurally, the two types of leaves diverged in the differentiation and arrangement directions of the mesophyll tissues (Fig. 1b), but unexpectedly shared consistent spatial parallel patterning for the vasculatures (Fig. 1c), which usually implies dorsoventrality in the leaf $[16,31]$. Therefore, the adaxial-abaxial polarity and the related specifying mechanism in the two types of leaves were studied by analyzing the Pinaceae homologs of the angiosperm polarity genes in the phylogenetic frame and spatiotemporal expression pattern in this study.

The HDZIPIII, AS1 and YABBY genes play central roles in the antagonistic interactions of genes for the specification of leaf polarity in angiosperms [22, 25, 38]. In the present study, phylogenetic analyses grouped the Pinaceae adaxial determinants HDZIPIII and abaxial determinant $Y A B B Y$ into 5 and 3 clades, respectively (Fig. 2 ). Interestingly, these polarity genes did not show any obvious divergence in terms of allocation and number between the species with two different types of leaves (Fig. 2c). Congruent with the phylogeny of HDZIPIII in land plants [40, 41], our results indicate that all HDZIPIII homologs of seed plants form a highly supported monophyletic group, in which a gymnosperm clade is at the most basal position, and two sister clades between gymnosperm and angiosperm occur (Fig. 2a). This 


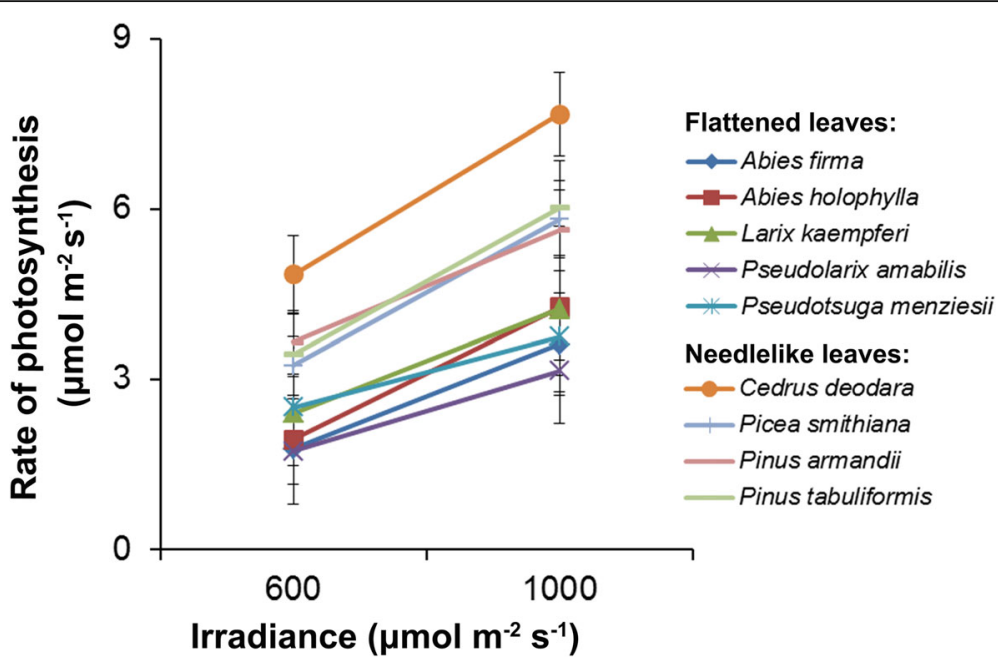

Fig. 4 Rate of photosynthesis for needlelike and flattened leaves under two gradients of irradiance. All measurements were made on newly expanded leaves of trees growing in the same conditions in late August. Data are means of three replicates. Error bars represent SD

evidence, along with other previous studies [40-42], suggests that the HDZIPIII gene family diversified during seed plant evolution. One AS1 member was identified in most of the Pinaceae species (Additional file 7: Figure S4), consistent with the fact that this gene exists as a single copy in most angiosperms [43-45]. Finet et al. (2016) [39] divided gymnosperm $Y A B B Y$ genes into four clades, of which three included Pinaceae genes. Consistently, in the present $Y A B B Y$ gene phylogeny, gymnosperm sequences are also distributed in three moderately supported clades, while the angiosperm sequences form an independent clade (Fig. 2b). Notably, the $Y A B B Y$ sequences generated from the transcriptome databases occur only in clades GymYAB_B and GymYAB_C (Fig. 2b), indicating the obligate function of these two clades for Pinaceae leaf development.

Increasing evidence from angiosperms supports that modifications of the expression patterns of polarity genes largely impact plant morphology, such as the trumpet leaves of the HDZIPIII double mutant and the narrow leaf blade of the $Y A B B Y$ triple mutants [20, 38, 46-49]. In the present study, according to the phylogenetic analysis (Fig. 2), GymC3HDZ_A, GymAS1 and GymYAB_C were used in the qPCR and in situ hybridization experiments. In Abies holophylla and Picea smithiana, the in situ expression of GymC3HDZ_A displayed evident signals in the adaxial region and the provascular strands (Fig. 3c). The same expression pattern was also found in Pseudotsuga menziesii and Ginkgo biloba [40, 41] as well as in ferns, but not in lycophytes [42], which indicates that the role in leaf adaxial specification and provascular differentiation may only occur within the euphyllophytes [40-42]. The other adaxial determinant AS1 homologs exhibited similar expression patterns constrained to the juxtaposition between the adaxial and abaxial domains (Fig. 3c), as is the case for its homolog in Arabidopsis [27]. In addition, the polar patterning of GymYAB_C was not found in the two types of leaves (Fig. 3c), which is similar to the results of a previous study on Pseudotsuga menziesii [39]. In addition to the in situ expression, the temporal expression by $\mathrm{qPCR}$ also indicates the critical functions of these polarity genes in Pinaceae leaf development (Fig. 3b and Additional file 8: Figure S5).

In conclusion, both the phylogenetic analyses and the spatiotemporal expression patterns indicate the existence of an evolutionarily conserved genetic network of polarity genes that confers adaxial-abaxial polarity in both the Pinaceae needlelike and flattened leaves.

\section{Pinaceae flattened and needlelike leaves have diverged for photosynthetic adaptation}

As the basis of life on Earth, photosynthesis is mainly determined by three factors, i.e., stomata conductance, mesophyll conductance and photo/biochemistry [35, 50, 51], all of which are closely linked to leaf morphology and structure. Along the evolution of land plants, leaf morphology and structure have changed greatly in parallel with the progressively increasing maximum photosynthesis rates, from the lowest values in bryophytes to the highest values in angiosperms $[52,53]$. In the present study, we found that the species with needlelike leaves generally exhibited better photosynthetic performance than the species with flattened leaves (Fig. 4 and and Additional file 9: Figure S6). Similar results were found in other studies. For instance, because of the difference in mesophyll conductance, the drought-adapted Abies pinsapo with needlelike amphistomatous leaves showed 
a higher photosynthetic rate than Abies alba with flattened, hypostomatous leaves in the mesic habitat [54]. Brodribb et al. (2007) [37] also found a higher photosynthetic capacity in needle-leaved Pinus species than in flat-leaved Podocarpaceae species, supporting the hypothesis that the length of the hydraulic pathway of the post-vein traverse through the mesophyll is negatively correlated with hydraulic conductivity as well as the $\mathrm{CO}_{2}$ assimilation rate. A recent study concluded that in gymnosperms, photosynthesis was mainly colimited by stomatal and mesophyll conductance [50]. Therefore, the divergence in photosynthesis of Pinaceae flattened and needlelike leaves could largely be attributed to the leaf structure that directly affects $\mathrm{CO}_{2}$ conductance.

In environments with the greatest sun exposure, especially those with concurrent stresses, such as water limitations, the leaf form appears to be more cylindrical with the radial, cross-section geometry [55]. Likely, the relatively dry habitats of the Northern Hemisphere shaped the needlelike, linear or scale-like leaves in Pinaceae and most Cupressaceae species that are characteristic of xeric habitats, while the warm and wet tropical forests in the Southern Hemisphere are more favorable for the development of bilaterally flattened foliage in Araucariaceae and Podocarpaceae [3, 56-58]. In addition, a phylogenetically based analysis suggested that Cupressaceae evolved from ancestors living in moist habitats with bilaterally flattened foliage to drought-resistant crown clades with appressed, imbricated leaves, accompanied by a reduced photosynthetic capacity because of the decreased xylem-specific conductivity $[6,59]$. Therefore, the different leaf morphologies were accompanied by divergent photosynthetic adaptation [5]. In Pinaceae, species with different types of leaves appear to have diverged in ecological niches. For instance, the genera Pinus, Picea and Cedrus with needlelike leaves are more suited to drought habitats than the genera with flattened leaves, such as Keteleeria and Tsuga, which inhabit warm temperate and subtropical forests [57]. Similarly, a recent study indicated that spruce with quadrangular leaves (sect. Picea) tend to be distributed in dry habitats, while those with flattened or broad triangular leaves (sect. Omorica and sect. Casicta) occur mainly in wet climates [60]. Based on the present study, the structure of dense mesophyll tissue, an almost multifaceted stomatal line and a high photosynthetic rate could help the species of Pinaceae with needlelike leaves live in drought-prone and sunny habitats (Fig. 1b and Fig. 4). In contrast, the porous mesophyll tissue, particularly the uniform palisade cells and relatively low photosynthetic rate, could allow the species with flattened leaves to survive in the humid and shady environment (Fig. 1b and Fig. 4). More studies related to the physiological and ecological attributes are needed to better understand the adaptive evolution of Pinaceae leaves.

\section{Conclusions}

Leaf developmental mechanisms have been studied extensively in angiosperms, but rarely in gymnosperms due to their long generation times and large genome sizes. In this study, based on a detailed morpho-anatomical study of leaves from all 11 Pinaceae genera, the expression patterns of adaxial-abaxial polarity genes were investigated in the delimited needlelike and flattened leaves of this family. We found that the two types of leaves share conserved spatial patterning of vasculatures and genetic networks for adaxial-abaxial polarity, although the differentiation and arrangement direction of the mesophyll tissues are different. In addition, the two types of leaves have diverged for photosynthetic adaptation with the needlelike leaves exhibiting better photosynthetic performance than the flattened leaves. Our study indicates the existence of an evolutionarily conserved genetic network of polarity genes that confers adaxial-abaxial polarity in both the needlelike and flattened leaves of Pinaceae.

\section{Methods \\ Plant materials}

Because leaf morphology is generally conserved within most genera of Pinaceae, a total of 16 species representing all 11 genera of Pinaceae were sampled (Additional file 10: Table S1). Sampling permissions were obtained from the corresponding botanical gardens and natural reserves. Sample identifications were performed according to the species signboard in the botanical gardens as well as and the records of Flora of China and some voucher specimens were deposited in our lab. More than one species was selected from both Picea and Pinus because both needlelike and flattened leaves occur in these two genera. In addition, two species of Abies were used to test the morphological variation within the genus, and two were studied from Tsuga due to the shortage of fresh materials. Each species was represented by 1-3 individuals. First, all samples, with the exception of Pinus armandii, were used to observe the morphology and anatomy by optical microscopy and scanning electron microscopy (SEM). Second, 5 species belonging to 4 genera representing flattened and needlelike leaves were used to analyze the expression of adaxial-abaxial polarity genes by qPCR. Then, Abies holophylla with flattened leaves and Picea smithiana with needlelike leaves were used in the in situ hybridization. Finally, based on the "common garden" conditions, 9 species representing 7 genera cultivated at the Institute of Botany, Chinese Academy of Sciences (IBCAS), were selected to measure the photosynthetic capacity. 


\section{Morphological and anatomical observations}

Current-year fresh mature leaves were used to observe the morphology and anatomy under a stereomicroscope (M205 C, Leica Camera AG, Germany). The width/ thickness ratio (WTR) of leaf cross section was introduced to classify leaves of different types. ImageJ software was used to measure the width and thickness of the photographed cross sections.

SEM (S-4800 FESEM, Hitachi, Japan) was used to magnify and clearly observe the mesophyll structure and leaf bud morphology. Fresh mature leaves and leaf buds of different developmental stages were collected and immediately fixed in FAA (Formalin-Acetic-Alcohol). The FAA solution was infiltrated for up to 30 min under vacuum and then stored at $4{ }^{\circ} \mathrm{C}$. Samples were dehydrated in a water-ethanol series and then put in a $\mathrm{CO}_{2}$ criticalpoint dryer. The dried materials were fixed on a small round table to be sputter-coated with gold. After that, the materials were examined with SEM.

In addition, because some sclereids were found in Pinus krempfii, Pseudotsuga menziesii and Nothotsuga longibracteata (see results), high-resolution threedimensional (3D) images of the internal and geometric structures of the leaves of these three species were reconstructed using a micro-computed tomography (micro-CT) scanner (Bruker SkyScan 1172, Bruker Corp., USA). The pretreatment of materials followed the above fixing and drying procedures used for the SEM observations. The dried materials were fixed on a cylindrical bench, which could rotate between the fixed X-ray source and the detector. The two-dimensional tomographic images were produced by computer-processed $\mathrm{X}$-rays, and the 3D images were generated by subsequent digital geometry processing. NRecon v.1.6 software and the embedded flight recorder were used to reconstruct the $3 \mathrm{D}$ structure and convert the slices into animated movies by rotating, translating or scaling the models.

\section{Data collection and phylogenetic reconstruction of polarity genes}

To confirm whether adaxial-abaxial polarity exists in different Pinaceae leaves, the homologs of HDZIPIII, AS1 and $Y A B B Y$ genes that play key roles in adaxial-abaxial polarity establishment were studied. HDZIPIII and AS1 represent the adaxial determinants $[20,22]$, and the $Y A B B Y$ genes are involved not only in the abaxial development but also in leaf expanding [21], which is important for understanding the developmental mechanism of the flattened leaves in Pinaceae. First, the polarity genes were identified from the available transcriptome databases of the 11 Pinaceae genera by tBLASTn, using the corresponding genes of Arabidopsis thaliana as queries. These transcriptomes were previously sequenced by our lab with leaf bud and/or mature leaves as the materials [11]. In addition, the genome databases of Picea abies, Pinus taeda, Pseudotsuga menziesii, Ginkgo biloba, Amborella trichopoda and Selaginella moellendorffii were also used for gene searches. Some previously identified HDZIPIII and YABBY sequences of Ginkgo biloba, Taxus globosa, Pseudotsuga menziesii, Pinus taeda, Selaginella kraussiana and Selaginella moellendorffii were also downloaded from GenBank [39, 40]. In addition, homologous sequences from three model angiosperm species, including Arabidopsis thaliana, Oryza sativa and Amborella trichopoda, were added to the analysis $[40,61]$. The accession numbers of all the sequences used in this study are shown in Additional file 11: Table S2.

To reconstruct the phylogenetic trees, the coding regions of the polarity genes were first aligned with MAFF $\mathrm{T}$ [62] and manually adjusted in BIOEDIT [63]. To delete poorly aligned positions, the aligned CDS sequences were processed through ZORRO [64] with a threshold of 4 . Then, nucleotide substitution saturation was tested for each codon position using DAMBE 5 [65], which suggested that all three codon positions were not saturated for these genes. Therefore, the CDS datasets were used for the following analyses. Maximum likelihood (ML) searches were performed using RAxML v.8.1 [66] under the GTRGAMMA model. One hundred bootstrap replicates were conducted for support estimation.

\section{RNA extraction and qPCR analysis}

To explore the expression patterns of the adaxial-abaxial polarity genes, we selected five representative species (Abies firma, Pseudotsuga menziesii, Pinus armandii, Pinus tabuliformis and Picea smithiana) of the flattened and needlelike leaves to perform qPCR analysis. $A S 1$ and some key members of the HDZIPIII and YABBY gene families were selected for analysis based on previous studies [22, 39-41] and the present phylogenetic reconstruction (Fig. 2). For HDZIPIII, all clades of the seed plant HDZIPIII genes, with the exception of GymC3HDZ_E, were selected (Fig. 2a). For $Y A B B Y$, only Gym $Y A B \_B$ and Gym $Y A B \_C$ genes were identified in the transcriptome sequences (Fig. 2b), and therefore, these two clades were selected. Primers were designed based on sequence alignments. In the developmental process of the Pinaceae leaves, three key stages (S1 to S3) were specifically considered, from the stage of leaf primordia (S1 in Fig. 3a) to the stage of acquiring the initial leaf morphology ( $\mathrm{S} 2$ in Fig. 3a) and finally the stage of middle-aged leaves (S3 in Fig. 3a). Fresh materials were dissected and immediately frozen in liquid nitrogen. Total RNA was extracted with an RNAprep Pure 
Plant Plus Kit (polysaccharides \& polyphenolics-rich) (DP441, TIANGEN, China).

Approximately $2 \mu \mathrm{g}$ of total RNA was reverse transcribed into cDNA using an RT-PCR kit (KR116, TIAN GEN, China). The qPCR analysis was performed on a StepOnePlus Real-Time PCR System (Life Technologies Corp., USA) with the TB Green ${ }^{\circ}$ Premix Ex Taq ${ }^{\mathrm{Tn}}$ reagent (RR420A, TAKARA, Japan). Quantification was performed using the $2^{-\triangle \mathrm{CT}}$ method and the data were normalized based on the quantity of the reference gene, ACTIN. The dissociation curves were analyzed in all amplifications.

\section{In situ hybridization}

To test whether the polarity genes also present the adaxial-abaxial expression pattern in the distinct Pinaceae leaves, the samples of Abies holophylla and Picea smithiana were used for in situ hybridization. Leaf primordial tissues were fixed in FAA or paraformaldehyde (PFA) for $12 \mathrm{~h}$ and then dehydrated in a graded ethanol series on ice. The dehydrated samples in $100 \%$ ethanol were replaced with a graded xylene series and finally embedded in paraplast (P3683, SIGMA). The gene-specific probes labeled by digoxigenin were generated according to the manufacturer's instructions for a DIG Northern Starter Kit (No. 12039672910, Roche). The probe length was usually approximately $200 \mathrm{bp}$. The whole procedure of in situ hybridization was carried out as described by Brewer [67] with some small modifications. Slides were examined and photographed on a Leica DM6 B microscope.

\section{Measurement of photosynthetic capacity}

The measurement of photosynthetic capacity was conducted on 8 species growing in IBCAS. Approximately 3-5 branches were cut from 2 to 3 trees of each species in late August and end-soaked in water before being measured in the lab. All measurements were collected from newly expanded leaves (approximately 3-6 leaves each time) with a portable gas-exchange and fluorescence system (GFS-3000, Walz, Germany). The environmental parameters were set as follows: an air-flow of $400 \mathrm{mmol} \mathrm{s}^{-1}$ through the chamber, a leaf temperature of $30{ }^{\circ} \mathrm{C}$, a $\mathrm{CO}_{2}$ concentration of $380 \mu \mathrm{mol} \mathrm{mol}^{-1}$, and two photosynthetically active radiation (PAR) gradients of 600 and $1000 \mathrm{mmol} \mathrm{m}^{-2} \mathrm{~s}^{-1}$. The measured leaves were then used to calculate the projected leaf area.

\section{Supplementary information}

Supplementary information accompanies this paper at https://doi.org/10. 1186/s12862-020-01694-5.

Additional file 1: Figure S1. Diverse morphologies of Pinaceae leaves. (a) Abies firma. (b) Abies holophylla. (c) Cathaya argyrophylla. (d) Keteleeria davidiana. (e) Larix kaempferi. (f) Nothotsuga longibracteata. (g) Pseudolarix amabilis. (h) Pseudotsuga menziesii. (i) Tsuga chinensis. (j) Cedrus deodara. (k) Picea smithiana. (I) Picea brachytyla var. complanata. (m) Pinus krempfii. (n) Pinus tabuliformis. Ads, adaxial side; Abs, abaxial side. Bars, $1 \mathrm{~mm}$.

Additional file 2: Figure S2. SEM micrographs of sclereids from leaves of Pinus krempfii (a), Pseudotsuga menziesii (b) and Nothotsuga longibracteata (c). Red arrows indicate the sclereids. Bars, $200 \mu \mathrm{m}$.

Additional file 3: Video S1. Sclereids of Pinus krempfii shown in Additional file 2: Figure S2a.

Additional file 4: Video S2. Sclereids of Pseudotsuga menziesii shown in Additional file 2: Figure S2b.

Additional file 5: Video S3. Sclereids of Nothotsuga longibracteata shown in Additional file 2: Figure S2C.

Additional file 6: Figure S3. Phloroglucinol staining of xylem in the needlelike leaves of Cedrus deodara (a), Picea smithiana (b), Pinus armandii (c) and Pinus tabuliformis (d). xy, xylem; ph, phloem. Bars, $100 \mu \mathrm{m}$.

Additional file 7: Figure S4. Sequence alignment of AS1 from seed plants.

Additional file 8: Figure S5. qPCR analyses of polarity genes in three leaf developmental stages of the flattened- and needlelike-leaved species.

Additional file 9: Figure S6. Stomatal conductance and transpiration rate for needlelike and flattened leaves under two gradients of irradiance. Data are means of three replicates.

Additional file 10: Table S1. Samples used in this study.

Additional file 11: Table S2. The accession numbers of all sequences used in this study.

\section{Abbreviations}

C3HDZ: Class III HD-ZIP; YAB: YABBY; SEM: Scanning electron microscopy: IBCAS: Institute of Botany, Chinese Academy of Sciences; microCT: microcomputed tomography; FAA: Formalin-Acetic-Alcohol; PFA: Paraformaldehyde; ML: Maximum likelihood; PAR: Photosynthetically active radiation

\section{Acknowledgements}

The authors sincerely thank Dr. Xiu-Ping Xu, Ms. Rong-Hua Liang and Ms. Chun-Yan Zhang from the Institute of Botany, Chinese Academy of Sciences for the excellent technical assistance on Micro-CT, microscopy observation and photosynthesis measurement, respectively. We also thank Mr. Wei-Tao Jin for his help on the phylogeny reconstruction.

\section{Authors' contributions}

XQW conceived the study. HD and XQW designed the study. HD performed most of the laboratory experiments and the data analysis. YYF participated in the sample pretreatment before the FAA fixation. HD, XQW and JHR wrote the manuscript. All authors have read and approved the manuscript.

\section{Funding}

This study was supported by Key Research Program of Frontier Sciences, CAS (QYZDJ-SSW-SMC027), National Key R\&D Program of China (Grant No. 2017YFA0605100), and National Natural Science Foundation of China (Grant No. 31330008).

Availability of data and materials

The new sequences identified in this study have been submitted to GenBank, with accession numbers shown in Additional file 2: Table S2.

Ethics approval and consent to participate Not applicable.

Consent for publication Not applicable.

Competing interests

The authors declare that they have no competing interests. 
Received: 2 July 2020 Accepted: 21 September 2020

Published online: 07 October 2020

\section{References}

1. Ran J-H, Shen T-T, Wang M-M, Wang X-Q. Phylogenomics resolves the deep phylogeny of seed plants and indicates partial convergent or homoplastic evolution between Gnetales and angiosperms. Proc R Soc B. 2018;285: 20181012.

2. Lu Y, Ran J-H, Guo D-M, Yang ZY, Wang X-Q. Phylogeny and divergence times of gymnosperms inferred from single-copy nuclear genes. PLoS One. 2014;9:e107679.

3. Leslie AB, Beaulieu JM, Rai HS, Crane PR, Donoghue MJ, Mathews S. Hemisphere-scale differences in conifer evolutionary dynamics. Proc Natl Acad Sci U S A. 2012;109:16217-21.

4. Farjon A. A handbook of the world's conifers (2 Vols.). Leiden: Brill; 2017.

5. Brodribb TJ, Feild TS, Jordan GJ. Leaf maximum photosynthetic rate and venation are linked by hydraulics. Plant Physiol. 2007;144:1890-8.

6. Pittermann J, Stuart SA, Dawson TE, Moreau A. Cenozoic climate change shaped the evolutionary ecophysiology of the Cupressaceae conifers. Proc Natl Acad Sci U S A. 2012:109:9647-52.

7. Dörken VM, Lepetit B. Morpho-anatomical and physiological differences between sun and shade leaves in Abies alba mill. (Pinaceae, Coniferales): a combined approach. Plant Cell Environ. 2018;41:1683-97.

8. Leslie AB, Losada JM. Reproductive ontogeny and the evolution of morphological diversity in conifers and other plants. Integr Comp Biol. 2019; 59:548-58.

9. Jankowski A, Wyka TP, Żytkowiak R, Nihlgård B, Reich PB, Oleksyn J, Kudo G. Cold adaptation drives variability in needle structure and anatomy in Pinus sylvestris L. along a 1,900 km temperate-boreal transect. Funct Ecol. 2017;31: 2212-23.

10. Eckenwalder JE. Conifers of the world: the complete reference. Oregon: Timber Press; 2009

11. Ran J-H, Shen T-T, Wu H, Gong X, Wang X-Q. Phylogeny and evolutionary history of Pinaceae updated by transcriptomic analysis. Mol Phylogenet Evol. 2018;129:106-16.

12. Nystedt B, Street NR, Wetterbom A, Zuccolo A, Lin Y-C, Scofield DG, Vezzi F, Delhomme N, Giacomello S, Alexeyenko A, et al. The Norway spruce genome sequence and conifer genome evolution. Nature. 2013; 497:579-84.

13. Inanc B, Anthony R, Jackman SD, Stephen P, Robin C, Taylor GA, Saint YMM, Keeling $\mathrm{Cl}$, Dana B, Vandervalk BP, et al. Assembling the $20 \mathrm{~Gb}$ white spruce (Picea glauca) genome from whole-genome shotgun sequencing data. Bioinformatics. 2013;29:1492-7.

14. Stevens KA, Wegrzyn J, Zimin A, Puiu D, Crepeau M, Cardeno C, Paul R, Gonzalez-lbeaz D, Koriabine M, Holtz-Morris A, et al. Sequence of the sugar pine megagenome. Genetics. 2016;204:1613-26.

15. Conklin PA, Strable J, Li S, Scanlon MJ. On the mechanisms of development in monocot and eudicot leaves. New Phytol. 2019:221:706-24.

16. Fukushima K, Hasebe M. Adaxial-abaxial polarity: the developmental basis of leaf shape diversity. Genesis. 2014:52:1-18.

17. Sanders H, Rothwell GW, Wyatt S. Paleontological context for the developmental mechanisms of evolution. Int J Plant Sci. 2007;168:719-28.

18. Kalve S, De Vos D, Beemster GTS. Leaf development: a cellular perspective. Front Plant Sci. 2014;5:362.

19. Waites R, Hudson A. Phantastica: a gene required for dorsoventrality of leaves in Antirrhinum majus. Development. 1995;121:2143-54.

20. Emery JF, Floyd SK, Alvarez J, Eshed Y, Hawker NP, Izhaki A, Baum SF, Bowman JL. Radial patterning of Arabidopsis shoots by class III HD-ZIP and KANAD/ genes. Curr Biol. 2003:13:1768-74

21. Siegfried KR, Eshed Y, Baum SF, Otsuga D, Drews GN, Bowman JL. Members of the YABBY gene family specify abaxial cell fate in Arabidopsis. Development. 1999;126:4117-28.

22. Machida C, Nakagawa A, Kojima S, Takahashi H, Machida Y. The complex of ASYMMETRIC LEAVES (AS) proteins plays a central role in antagonistic interactions of genes for leaf polarity specification in Arabidopsis. Wires Dev Biol. 2015;4:655-71.

23. Pekker I, Alvarez JP, Eshed Y. Auxin response factors mediate Arabidopsis organ asymmetry via modulation of KANADI activity. Plant Cell. 2005;17: 2899-910.

24. Townsley BT, Sinha NR. A new development: evolving concepts in leaf ontogeny. Annu Rev Plant Biol. 2012;63:535-62.
25. Prigge MJ, Otsuga D, Alonso JM, Ecker JR, Drews GN, Clark SE. Class III homeodomain-leucine zipper gene family members have overlapping, antagonistic, and distinct roles in Arabidopsis development. Plant Cell. 2005; 17:61-76.

26. Kidner CA, Martienssen RA. Spatially restricted microRNA directs leaf polarity through ARGONAUTE1. Nature. 2004:428:81-4.

27. Iwakawa H, Iwasaki M, Kojima S, Ueno Y, Soma T, Tanaka H, Semiarti E, Machida Y, Machida C. Expression of the ASYMMETRIC LEAVES2 gene in the adaxial domain of Arabidopsis LEAVES represses cell proliferation in this domain and is critical for the development of properly expanded leaves. Plant J. 2007:51:173-84.

28. Garcia D, Collier SA, Byrne ME, Martienssen RA. Specification of leaf polarity in Arabidopsis via the trans-acting siRNA pathway. Curr Biol. 2006;16:933-8.

29. Iwasaki M, Takahashi H, Iwakawa H, Nakagawa A, Ishikawa T, Tanaka H, Matsumura Y, Pekker I, Eshed Y, Vial-Pradel S, et al. Dual regulation of ETTIN (ARF3) gene expression by AS1-AS2, which maintains the DNA methylation level, is involved in stabilization of leaf adaxial-abaxial partitioning in Arabidopsis. Development. 2013;140:1958-69.

30. Franck DH. The morphological interpretation of epiascidiate leaves-An historical perspective. Bot Rev. 1976:42:345-88.

31. Yamaguchi T, Yano S, Tsukaya H. Genetic framework for flattened leaf blade formation in unifacial leaves of Juncus prismatocarpus. Plant Cell. 2010;22: $2141-55$

32. Yamaguchi T, Tsukaya H. Evolutionary and developmental studies of unifacial leaves in monocots: Juncus as a model system. J Plant Res. 2010; 123:35.

33. Zimin A, Stevens KA, Crepeau MW, Holtz-Morris A, Koriabine M, Marçais G Puiu D, Roberts M, Wegrzyn JL, de Jong PJ, et al. Sequencing and assembly of the 22-Gb loblolly pine genome. Genetics. 2014;196:875-90.

34. Harrison CJ, Morris JL. The origin and early evolution of vascular plant shoots and leaves. Phil Trans R Soc B. 2018:373:20160496.

35. Flexas J, Carriquí M. Photosynthesis and photosynthetic efficiencies along the terrestrial plant's phylogeny: lessons for improving crop photosynthesis. Plant J. 2020;101:964-78.

36. Brodribb TJ, Feild TS, Sack L. Viewing leaf structure and evolution from a hydraulic perspective. Funct Plant Biol. 2010;37:488-98.

37. Brodribb TJ, Feild TS. Evolutionary significance of a flat-leaved Pinus in Vietnamese rainforest. New Phytol. 2007;178:201-9.

38. Sarojam R, Sappl PG, Goldshmidt A, Efroni I, Floyd SK, Eshed Y, Bowman JL. Differentiating Arabidopsis shoots from leaves by combined YABBY activities Plant Cell. 2010;22:2113-30.

39. Finet C, Floyd SK, Conway SJ, Zhong B, Scutt CP, Bowman JL. Evolution of the YABBY gene family in seed plants. Evol Dev. 2016;18:116-26.

40. Floyd SK, Zalewski CS, Bowman JL. Evolution of class III homeodomainleucine zipper genes in streptophytes. Genetics. 2006;173:373-88.

41. Prigge MJ, Clark SE. Evolution of the class III HD-Zip gene family in land plants. Evol Dev. 2006;8:350-61

42. Vasco A, Smalls TL, Graham SW, Cooper ED, Wong KS, Stevenson DW, Moran RC, Ambrose BA. Challenging the paradigms of leaf evolution: class III HD-zips in ferns and lycophytes. New Phytol. 2016;212:745-58.

43. Byrne ME, Barley R, Curtis M, Arroyo JM, Dunham M, Hudson A, Martienssen RA. Asymmetric leaves 1 mediates leaf patterning and stem cell function in Arabidopsis. Nature. 2000;408:967-71.

44. Timmermans MCP, Hudson A, Becraft PW, Nelson T, ROUGH SHEATH2: a Myb protein that represses knox homeobox genes in maize lateral organ primordia. Science. 1999;284:151-3.

45. Waites $\mathrm{R}$, Selvadurai $\mathrm{H}$, Oliver I, Hudson A. The PHANTASTICA gene encodes a MYB transcription factor involved in growth and dorsoventrality of lateral organs in Antirrhinum. Cell. 1998:93:779-89.

46. McConnell JR, Emery J, Eshed Y, Bao N, Bowman J, Barton MK. Role of PHABULOSA and PHAVOLUTA in determining radial patterning in shoots. Nature. 2001:411:709-13.

47. Xu L, Xu Y, Dong A, Sun Y, Pi L, Xu Y, Huang H. Novel as 1 and as2 defects in leaf adaxial-abaxial polarity reveal the requirement for ASYMMETRIC LEAV ES1 and 2 and ERECTA functions in specifying leaf adaxial identity. Development. 2003;130:4097-107.

48. McConnell JR, Barton MK. Leaf polarity and meristem formation in Arabidopsis. Development. 1998;125:2935-42.

49. Ueno Y, Ishikawa T, Watanabe K, Terakura S, Iwakawa H, Okada K, Machida C, Machida Y. Histone deacetylases and ASYMMETRIC LEAVES2 are involved 
in the establishment of polarity in LEAVES of Arabidopsis. Plant Cell. 2007;19: 445-57.

50. Gago J, Carriquí M, Nadal M, Clemente-Moreno MJ, Coopman RE, Fernie AR, Flexas J. Photosynthesis optimized across land plant phylogeny. Trends Plant Sci. 2019;24:947-58.

51. Flexas J, Barbour MM, Brendel O, Cabrera HM, Carriquí M, Díaz-Espejo A, Douthe C, Dreyer E, Ferrio JP, Gago J, et al. Mesophyll diffusion conductance to $\mathrm{CO}_{2}$ : an unappreciated central player in photosynthesis. Plant Sci. 2012;193:70-84

52. Carriquí M, Roig-Oliver M, Brodribb TJ, Coopman R, Gill W, Mark K, Niinemets Ü, Perera-Castro AV, Ribas-Carbó M, Sack L, et al. Anatomical constraints to nonstomatal diffusion conductance and photosynthesis in lycophytes and bryophytes. New Phytol. 2019;222:1256-70.

53. Carriquí M, Cabrera H, Conesa M, Coopman R, Douthe C, Gago J, Gallé A, Galmés J, Ribas-Carbó M, Tomás M, et al. Diffusional limitations explain the lower photosynthetic capacity of ferns as compared with angiosperms in a common garden study. Plant Cell Environ. 2015;38:448-60.

54. Peguero-pina JJ, Flexas J, Galmes J, Niinemets U, Sancho-Knapik D, Barredo G, Villarroya D, Gil-Pelegrin E. Leaf anatomical properties in relation to differences in mesophyll conductance to $\mathrm{CO}_{2}$ and photosynthesis in two related Mediterranean Abies species. Plant Cell Environ. 2012;35:2121-9.

55. Smith WK, Vogelmann TC, H. DE, Bell DT, Shepherd KA. Leaf form and photosynthesis. Bioscience. 1997;47:785-93.

56. Farjon A. Monograph of Cupressaceae and Sciadopitys. Kew: Royal Botanic Gardens, Kew; 2005.

57. Farjon A. A handbook of the World's conifers. Leiden: Brill; 2010.

58. Biffin E, Brodribb TJ, Hill RS, Thomas P, Lowe AJ. Leaf evolution in southern hemisphere conifers tracks the angiosperm ecological radiation. Proc $R$ Soc B. 2012;279:341-8

59. Gadek PA, Alpers DL, Heslewood MM, Quinn CJ. Relationships within Cupressaceae sensu lato: a combined morphological and molecular approach. Am J Bot. 2000;87:1044-57.

60. Wang G-H, Zhao H-W, An M, Li H, Zhang W-K. Detecting the driving forces underlying the divergence of spruce forests in China: evidence from phytocoenology, morphology and phylogenetics. J Plant Ecol. 2019;13:59-69.

61. Bartholmes C, Hidalgo O, Gleissberg S. Evolution of the YABBY gene family with emphasis on the basal eudicot Eschscholzia californica (Papaveraceae). Plant Biol. 2012;14:11-23.

62. Katoh K, Standley DM. MAFFT multiple sequence alignment software version 7: improvements in performance and usability. Mol Biol Evol. 2013; 30:772-80.

63. Hall TA. BioEdit: a user-friendly biological sequence alignment editor and analysis program for windows 95/98/NT. Nucleic Acids Symp. 1999:41:95-8.

64. Wu M, Chatterji S, Eisen JA. Accounting for alignment uncertainty in phylogenomics. PLoS One. 2012;7:e30288.

65. Xia X. DAMBE5: a comprehensive software package for data analysis in molecular biology and evolution. Mol Biol Evol. 2013;30:1720-8.

66. Stamatakis A. RAxML version 8: a tool for phylogenetic analysis and postanalysis of large phylogenies. Bioinformatics. 2014;30:1312-3.

67. Brewer PB, Heisler MG, Hejátko J, Friml J, Benková E. In situ hybridization for mRNA detection in Arabidopsis tissue sections. Nat Protoc. 2006;1:1462-7.

\section{Publisher's Note}

Springer Nature remains neutral with regard to jurisdictional claims in published maps and institutional affiliations.

Ready to submit your research? Choose BMC and benefit from:

- fast, convenient online submission

- thorough peer review by experienced researchers in your field

- rapid publication on acceptance

- support for research data, including large and complex data types

- gold Open Access which fosters wider collaboration and increased citations

- maximum visibility for your research: over $100 \mathrm{M}$ website views per year

At $\mathrm{BMC}$, research is always in progress.

Learn more biomedcentral.com/submissions 